\title{
Constituintes Frasais com Função de Sujeito em Sentenças Judiciais
}

\author{
Ester Motta ${ }^{1}$; Maria José Bocorny Finatto ${ }^{2}$ \\ Programa de Pós-Graduação em Letras - Universidade Federal do Rio Grande \\ do Sul (UFRGS) - 91.501-970 - Porto Alegre - RS - Brasil \\ lestermottac@gmail.com; 2mariafinatto@gmail.com
}

\begin{abstract}
Resumo. Descreve-se a organização sintática de um conjunto de Sentenças dos Juizados Especiais Cíveis, cujos documentos devem ser acessiveis ao cidadão leigo, sem auxílio de um advogado. São destacados os constituintes frasais com função de sujeito em 110 Sentenças à luz dos estudos de Terminologia, da Linguística de Corpus e de pesquisas sobre compreensão leitora. Verificou-se que a maioria desses constituintes assume formas que tendem a demandar maior sobrecarga na leitura e a exibir traços pouco coincidentes com padrões da linguagem cotidiana escrita, o que dificulta sua inteligibilidade para o público leigo.
\end{abstract}

\begin{abstract}
This work describes the syntactic organization of a set of Judgments of the Special Civil Courts, whose documents must be accessible to the lay citizen without the assistance of a lawyer. The phrasal constituents with subject function in 110 Judgments are highlighted in the light of Terminology studies, Corpus Linguistics and research on reading comprehension. The study found that most of these constituents assume forms that tend to demand greater burden in reading and to exhibit traits that hardly coincide with patterns of written daily language, which makes their intelligibility difficult for the lay public.
\end{abstract}

\section{Introdução}

Este trabalho traz dados de um estudo-piloto realizado em uma pesquisa de doutorado em andamento junto ao Programa de Pós-Graduação da Universidade Federal do Rio Grande do Sul. A pesquisa procura gerar dados descritivos sobre a maior ou menor acessibilidade da linguagem em uso em Sentenças ${ }^{1}$ dos Juizados Especiais Cíveis (JECs) do Poder Judiciário do Estado do Rio Grande do Sul (PJRS). O estudo-piloto concerne ao tema da complexidade sentencial e sintática desses documentos.

Os JECs foram criados em 1995, pela Lei n. 9.099, para fornecer uma resposta mais rápida da Justiça ao cidadão, com um trâmite processual menos complexo, dispensando-se a atuação de advogados em alguns casos. Os documentos produzidos por esses juizados, conhecidos como "tribunais de pequenas causas", deveriam ser acessíveis ao entendimento do cidadão leigo, prevendo-se que esteja desacompanhado de advogado.

Nesse contexto, os dados do estudo aqui apresentado têm por objetivo descrever

\footnotetext{
${ }^{1}$ Quando nos referimos às Sentenças dos JECs, escreveremos com iniciais maiúsculas, para diferenciá-las das outras acepções dadas a esta palavra, tal como o significado de frase e sentença.
} 
a conformação sentencial e sintática de uma amostra de Sentenças dos JECS do PJRS, destacando-se a apresentação dos constituintes frasais com função de sujeito (doravante CFsSujeitos). A escolha pelo exame centrado nos CFsSujeitos deu-se porque, segundo Fulgêncio e Liberato (2010), autoras que tomamos como referência para o exame dos dados quanto à complexidade de leitura, a medida ou extensão desses constituintes da sentença, individualmente, é muito importante, pois formam unidades centrais para a construção do significado. Além disso, a sintaxe verificada nas frases dessas Sentenças nos parece, prima facie, bastante complexa, merecendo uma abordagem à parte. Para ilustrar essa impressão, trazemos o exemplo (1), a seguir. Trata-se de uma única frase com 101 palavras $^{2}$ e vários níveis de subordinação. O trecho em negrito representa um CFSujeito com 56 palavras.

(1) De fato, embora não exista contrato expresso que demonstre o negócio jurídico realizado entre as partes, concluo que os depósitos efetuados pelo réu em benefício do autor (fl. 34), aliados às fotos de fls. 42 e 43 e aos emails trocados entre as partes (fls. 28, 30 e 31), em especial, o e-mail de fl. 28 no qual o requerido confirma que os pagamentos seriam realizados de acordo com a realização da Obra, (sic) corroboram a versão inicial, no sentido de que autor e requerido ajustaram a construção de uma casa, que seria paga de modo parcelado até o final da obra. (Processo: 9002991-14.2018.8.21.0029- RIO GRANDE DO SUL, 2019, grifos nossos.)

Assim, pretende-se estudar o quanto e como a organização sintática dessas Sentenças, a partir do constituinte escolhido (CFsSujeitos), tenderia a: a) influenciar a complexidade textual; b) contribuir para um modus dicendi peculiar dos discursos do domínio jurídico brasileiro. Objetivamos, assim, verificar, pontualmente, se os critérios norteadores das ações dos $\mathrm{JECs}^{3}$ - oralidade, simplicidade, informalidade, celeridade são atendidos pela configuração da linguagem empregada nos textos de suas Sentenças.

\section{Referenciais teóricos e metodológicos}

Nossa pesquisa envolve diversas áreas do conhecimento, como Linguística Textual, Psicolinguística, Linguística de Corpus, Estudos do Léxico, Terminologia, Acessibilidade Textual e Terminológica e Tradução Intralinguística. Valemo-nos também de ferramentas e métodos computacionais do Processamento da Linguagem Natural (PLN) para a coleta e descrição dos dados textuais.

Entre os estudos de PLN, servimo-nos dos importantes subsídios trazidos por Leal (2019), que analisou, extensivamente, a complexidade sentencial do português brasileiro escrito, usando métricas linguísticas, psicolinguísticas e de rastreamento ocular. Este pesquisador afirma que a complexidade de uma sentença está relacionada a fatores como: extensão da sentença, extensão dos seus elementos constituintes, ordem dos elementos da sentença, presença de anáforas, etc.

Ao analisar Sentenças dos JECs do PJRS, lidamos com a linguagem de um dos domínios do conhecimento humano, o Direito. Nos estudos linguísticos, os variados tipos de textos desse domínio já são analisados por diferentes teorias do texto e do discurso e

\footnotetext{
${ }^{2}$ Palavra, neste trabalho, é vista como uma unidade da língua escrita situada entre dois espaços em branco, ou entre espaço em branco e sinal de pontuação.

${ }^{3}$ Tais princípios encontram-se relacionados no art. $2^{\circ}$ da Lei n. 9.099, de 1995.
} 
também pela ótica da Terminologia. Entre os estudos terminológicos, filiamo-nos à Terminologia de perspectiva textual e comunicativa [Bourigault e Slodzian 2004; Krieger e Finatto 2004]. Isso significa que examinamos não apenas o léxico temático, mas toda a textualidade dos diferentes tipos de discursos especializados, o que inclui a semântica e a sintaxe textual e frasal, como o que analisamos nas Sentenças dos JECs.

\subsection{Materiais e Métodos}

Trabalhamos com 110 Sentenças do corpus de estudo (CE) do todo da pesquisa, que tem 440 Sentenças. São documentos exarados entre 2018 e 2019. A amostra, selecionada de modo aleatório, buscou incluir os diferentes temas neles tratados. A Tabela 1 caracteriza o CE e a amostra fixada.

Tabela 1. Dados do CE e da Amostra

\begin{tabular}{|l|r|r|}
\hline & \multicolumn{1}{|c|}{$\begin{array}{c}\text { CORPUS DE } \\
\text { ESTUDO (CE) }\end{array}$} & \multicolumn{1}{c|}{ AMOSTRA } \\
\hline TOTAL DE TEXTOS & 440 & 710 \\
\hline TOTAL DE FRASES & $31.601,52$ & 7.491 \\
\hline PALAVRAS POR FRASE & 18,22 & 19,25 \\
\hline TOTAL DE TOKENS & 543.407 & 137.700 \\
\hline TOTAL DE TYPES & 15.388 & 8.477 \\
\hline HAPAX & 5.258 & 3.239 \\
\hline
\end{tabular}

A ferramenta utilizada para a geração do número de tokens (palavras do texto), de types (palavras diferentes do texto) e de hapax legomenon (palavras de frequência única no texto) foi o sistema AntConc 3.2.1w. ${ }^{4}$. Esse é um software livre que fornece listas de palavras, clusters, listas de contextos, e outras utilidades para análise linguística. Para verificar o total de frases e o total de palavras por frase, utilizamos a ferramenta NilcMetrix $^{5}$ (Coh-Metrix 3.0, nova versão de 2020). As métricas oferecidas pelo NILCMetrix analisam a inteligibilidade do texto e foram desenvolvidas em mais de uma década no NILC da USP, campus de São Carlos.

A Tabela 1 acima permite verificar que, em relação ao CE, a amostra apresenta percentuais próximos a $25 \%$ no que se refere a número de: textos $(25 \%)$, tokens $(24,3 \%)$ e frases $(23,7 \%)$. O número de palavras por frase da amostra, por sua vez, é semelhante ao do $\mathrm{CE}$, com apenas 1 palavra a mais. Em relação ao hapax legomenon, que evidencia as especificidades e as preferências lexicais do autor de um texto, o percentual de ocorrência ficou muito semelhante nos dois conjuntos de textos: $34,17 \%$ no CE (5.258 para 15.385 types); e 38,20\% na amostra (3.239 para 8.477 types). Tais dados permitem concluir pela representatividade da amostra em relação ao CE nesses quesitos. Salientamos, porém, que esses dados não influíram na fixação prévia da amostra.

\footnotetext{
${ }^{4}$ Disponível em <http://www.laurenceanthony.net/software.html $>$

${ }^{5}$ Disponível em: 〈http://fw.nilc.icmc.usp.br:23380/nilcmetrix >
} 


\subsection{Análise e Processamento dos Dados}

Nossa unidade de análise foi a sentença/frase demarcada por uma inicial maiúscula e ponto final. A partir de cada sentença, identificamos orações e seus constituintes. Entendemos como constituintes da sentença os elementos da oração que formam com o verbo uma estrutura de argumentos ou valência verbal.

No exame inicial da amostra, as análises sentenciais e oracionais foram manuais, sem um apoio computacional específico para a geração de árvores de dependência ou parsing. Isso foi feito com base no nosso conhecimento sobre análise sintática como linguistas com o propósito de gerar uma referência ou goldstandard para as análises automáticas com o todo do CE. Assim, lemos e classificamos cada uma das orações presentes em nossa amostra e delas extraímos os CFsSujeitos.

\section{Resultados da análise e classificação dos CFsSujeitos}

Após identificar os CFsSujeitos, classificamo-los da seguinte forma: a) pré-verbal (sujeitos colocados antes do verbo); pós-verbal (sujeitos colocados após o verbo); b) pronominal (sujeitos representados por pronomes - relativos, demonstrativos, retos, etc.); c) elíptico em duas situações - quando determinado pela flexão número-pessoa do verbo ou por sua presença em alguma oração antecedente -; e d) oracional (oração como sujeito de outro verbo).

A classificação quanto à posição do sujeito - pré ou pós-verbal - deu-se apenas em relação aos CFsSujeitos constituídos por sintagmas nominais.

Na Tabela 2, temos o total de CFsSujeitos selecionados com a quantidade encontrada para cada tipo.

Tabela 2. Ocorrências dos tipos de sujeitos da Amostra

\begin{tabular}{|c|c|c|c|c|c|}
\hline \multicolumn{6}{|c|}{ TIPOS DE SUJEITOS } \\
\hline & ELÍPTICOS & \multicolumn{4}{|c|}{ REALIZADOS } \\
\hline & & \multicolumn{2}{|c|}{$\begin{array}{l}\text { SINTAGMA } \\
\text { NOMINAL }\end{array}$} & \multirow[t]{3}{*}{ PRONOMINAL } & \multirow[t]{3}{*}{ ORACIONAL } \\
\hline & & Pré-Verbal & 3.869 & & \\
\hline & & Pós-Verbal & 1.884 & & \\
\hline & & & 5.753 & 1.459 & 486 \\
\hline SUBTOTAL & 4.159 & & & & 7.698 \\
\hline TOTAL & & & & & 11.857 \\
\hline
\end{tabular}

Conforme a Tabela 2, os sujeitos realizados são os de maior ocorrência na amostra, porém os sujeitos elípticos representam 35,07\% do total de CFsSujeitos da amostra. Além disso, os sujeitos pós-verbais estão em terceiro lugar no ranking. Tais dados permitem-nos fazer algumas inferências.

Estudos sobre compreensão leitora (Fulgêncio e Liberato 2010) já assinalaram que sujeitos pós-verbais e elípticos podem ser considerados fator de maior complexidade, pois requerem sobrecarga maior de memória de trabalho. Os pós-verbais, que não estão 
na ordem canônica da língua (sujeito-verbo-complementos), vão contra um processamento natural da leitura. O leitor busca, em seus conhecimentos linguísticos, estruturas sintagmáticas que lhe sejam mais conhecidas e, em encontrando, este conhecimento prévio favorece a compreensão. É o que diz Coscarelli (2002, p. 14)

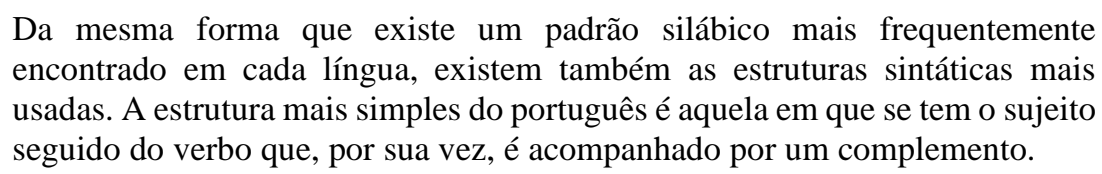

E os sujeitos elípticos, por demandarem a busca pelo seu referente, tornam essa identificação mais complexa que a identificação de um sujeito explícito na oração. E isso sobrecarrega a memória de trabalho na leitura.

Após essa classificação inicial, adotamos dois procedimentos.

\section{Procedimento 1:}

Distribuímos os sujeitos pré-verbais, pós-verbais e oracionais por número de palavras para verificar a extensão das dependências sintáticas: o número de palavras entre a raiz sintática (no caso, o SV) e o dependente (no caso, o constituinte com função de sujeito). A Tabela 3 apresenta esses dados.

Tabela 3. CFsSujeitos por número de palavras

\begin{tabular}{|l|r|r|r|}
\hline \multirow{2}{*}{$\begin{array}{c}\text { QUANTIDADE } \\
\text { PALAVRAS }\end{array}$} & \multicolumn{3}{|c|}{ NÚMERO DE OCORRÊNCIAS } \\
\cline { 2 - 4 } & PRÉ-VERBAIS & PÓS-VERBAIS & ORACIONAIS \\
\hline $1 \mathrm{a} 10$ & 3654 & 1453 & 151 \\
\hline $11 \mathrm{a} 20$ & 176 & 320 & 186 \\
\hline $21 \mathrm{a} 30$ & 31 & 77 & 82 \\
\hline $30 \mathrm{ou}+$ & 8 & 34 & 67 \\
\hline TOTAL & 3869 & 1884 & 486 \\
\hline
\end{tabular}

Pela Tabela 3, é possível verificar que a maioria dos sujeitos analisados fica na faixa de 1 a 10 palavras. A exceção está quanto ao sujeito oracional. E isso é previsível porque, em tese, a oração vai ter mais palavras que sintagmas nominais simples.

Apesar dessa alta incidência de sujeitos na faixa de 1 a 10 palavras, a maioria dos sujeitos pré e pós-verbais apresenta seus núcleos expandidos por encaixes oracionais, mais próximos do limite de 10 itens, como se vê nos exemplos a seguir.

(2) Digressões abstratas [de que o procedimento esteja excluído] não representa (sic) prova efetiva que autoriza a falta de cobertura securitária.

(3) Devido, pois, o reembolso daquilo [que o contratante despendeu com o procedimento] cuja cobertura foi negada pela seguradora]].

O exemplo (2) apresenta 8 palavras, sendo 6 representadas por uma oração relativa nele encaixada. Essa estrutura sobrecarrega a memória de trabalho do leitor, porque ele 
precisa processar várias informações antes de chegar à principal. A falta de concordância verbal "não representa" ao invés de "não representam", evidencia essa situação. A memória de curto prazo, ao ter de processar a informação trazida pela encaixada [de que o procedimento esteja excluído], não conseguiu manter o núcleo plural do sujeito digressões -, e aparentemente relacionou o verbo com o sujeito da encaixada: procedimento.

No exemplo (3), o complemento do núcleo "daquilo" é uma oração relativa encaixada que, por sua vez, também apresenta uma palavra expandida por outra oração relativa encaixada, esta iniciada pelo pronome "cuja", pouco usual no cotidiano da Língua Portuguesa. Ou seja, é um constituinte complexo com vários encaixes hierarquicamente diferentes e apresenta também um nexo pouco frequente na língua. Segundo Fulgêncio e Liberato (2010, p. 141), "a quantidade de encaixamentos é outro ponto que causa a complexidade das estruturas e faz com que elas sejam mais difíceis de serem processadas".

O exemplo (4) reproduz um sujeito oracional.

(4) No caso concreto, verifica-se que não se constata a verossimilhança das alegações da autora quanto à alegada falha por parte da empresa requerida quanto à perfectibilização de um plano em linha de telefonia móvel da autora diversa daquela [em relação à qual a consumidora pretendia fosse efetuado o plano], assim como, (sic) não se constata a verossimilhança da alegação da mesma no [que se refere ao fato [de que possuía duas linhas de telefonia móvel, tampouco junto à empresa requerida]].

O exemplo (4) traz um sujeito oracional composto relacionado pela conjunção assim como. A primeira oração, iniciada em que não se constata, apresenta 45 palavras. A segunda, iniciada com assim como, apresenta 31 palavras. O trecho todo é composto por 81 palavras organizadas em apenas 1 frase com vários constituintes de hierarquia, fator considerado dificultador para a compreensão leitora.

\section{Procedimento 2:}

Verificamos a forma como se apresentavam os sujeitos elípticos, os sujeitos oracionais e os sujeitos pronominais. A Tabelas 4 resume esses dados da amostra. 
Tabela 4. Formas como se apresentam os CFsSujeitos elípticos, oracionais e pronominais na Amostra

\begin{tabular}{|c|c|c|c|c|c|}
\hline \multicolumn{2}{|c|}{ SUJEITOS ELÍPTICOS } & \multicolumn{2}{|c|}{ SUJEITOS ORACIONAIS } & \multicolumn{2}{|c|}{ SUJEITOS PRONOMINAIS } \\
\hline $\begin{array}{l}\text { FORMAS } \\
\text { VERBAIS }\end{array}$ & Oorrências & $\begin{array}{l}\text { Como se } \\
\text { apresenta }\end{array}$ & Ocorrências & $\begin{array}{l}\text { Tipo de } \\
\text { pronome }\end{array}$ & Ocorrências \\
\hline $\begin{array}{l}\text { Verbos na } \\
3^{\text {a }} \text { pessoa }\end{array}$ & 1734 & $\begin{array}{l}\text { Oração } \\
\text { desenvolvida } \\
\text { (com } \\
\text { conjunção) }\end{array}$ & 265 & $\begin{array}{l}\text { Relativos (que, } \\
\text { quem, qual) }\end{array}$ & 1020 \\
\hline $\begin{array}{l}\text { Verbos na } \\
1^{\text {a }} \text { pessoa }\end{array}$ & 664 & $\begin{array}{l}\text { Oração } \\
\text { reduzida }\end{array}$ & 221 & Demonstrativos & 230 \\
\hline $\begin{array}{l}\text { Verbos no } \\
\text { Infinitivo }\end{array}$ & 887 & & & Retos & 38 \\
\hline $\begin{array}{l}\text { Verbos no } \\
\text { Gerúndio }\end{array}$ & 592 & & & Mesmo $^{6}$ & 103 \\
\hline $\begin{array}{l}\text { Verbos no } \\
\text { Particípio }\end{array}$ & 282 & & & Indefinidos & 68 \\
\hline TOTAL & 4159 & & 486 & & 1459 \\
\hline
\end{tabular}

Quanto às formas dos sujeitos elípticos, os que se encontram com os verbos na $3^{\text {a }}$ pessoa são os de maior frequência em nossa amostra. Dentro desse grupo, 1.577 verbos estão na $3^{\text {a }}$ pessoa do singular e 157 estão na $3^{a}$ pessoa do plural. Estando o verbo na forma finita, em princípio a busca pelo seu referente fica mais acessível. Em relação aos verbos flexionados na $1^{a}$ pessoa, a grande maioria deles se refere ao redator do texto, sendo possível depreender essa informação pelo contexto situacional.

As outras formas verbais relativas a sujeitos elípticos são nominais. Abaixo apresentamos alguns exemplos.

(5) Citada (folha 83), a parte Requerida contestou o feito (folhas 81/104). Alegou que o poste da rede de energia foi instalado no local há anos [...]

No exemplo (5), a forma verbal "citada", num processo catafórico, refere-se ao sujeito "a parte requerida". Segundo Fulgêncio e Liberato (2010), a catáfora implica uma sobrecarga na memória de curto prazo, porque exige que o item reduzido tenha de ser guardado na memória até que seu referente apareça no texto. Isso, consequentemente, acarreta maior trabalho para o leitor e maior dificuldade na leitura.

E a forma verbal "alegou" retoma este mesmo sujeito por um processo anafórico. Ainda segundo as autoras Fulgêncio e Liberato (2010), a busca de um referente na anáfora pode prejudicar a legibilidade do texto. Se essa relação for transparente - os referentes sendo facilmente identificados -, a leitura segue sem problemas. Porém, havendo dificuldade de encontrar o referente, "a leitura pode ser atrasada ou até mesmo interrompida" [Fulgêncio e Liberato 2010, p. 85]. É o que ocorre no exemplo (6), a seguir.

\footnotetext{
${ }^{6}$ Colocamos "mesmo" separadamente, porque atua diversamente na amostra - ora como pronome reto, ora como pronome demonstrativo.
} 
(6) Restou comprovado nos autos a culpa exclusiva do demandado, que invadiu a via preferencial pela qual a demandante trafegava, desrespeitando a sinalização e a preferencialidade da via [...]

O gerúndio "desrespeitando", destacado no exemplo (6), pode, numa leitura inicial, ser atribuído à "demandante", que consta na oração imediatamente anterior. Todavia, essa interpretação é incoerente com o contexto.

Como vemos na Tabela 5, a diferença entre as ocorrências relativas às orações reduzidas e desenvolvidas é de aproximadamente 9\%. Cabe ressaltar que as orações reduzidas, por apresentarem o verbo no infinitivo em sua maioria sem flexão (apenas 2 situações de infinitivo flexionado) podem ser um fator dificultador para a leitura, visto que se torna mais difícil de encontrar um elemento textual ou situacional referente a ele.

Quanto aos sujeitos pronominais, pela Tabela 6, verificamos que os pronomes relativos (que, quem e qual) ocupam o primeiro lugar (69\%) entre os sujeitos pronominais. Além disso, as 1020 ocorrências de pronomes relativos na função de sujeito indicam a existência de 1020 orações relativas encaixadas. Já mencionamos que as orações encaixadas agregam informação aos constituintes da oração anterior, o que demanda maior custo de processamento na leitura e, em princípio, oferece maior dificuldade para a compreensão.

A seguir, a Tabela 5 apresenta uma síntese dos CFsSujeitos encontrados na amostra.

Tabela 7. Síntese dos CFsSujeitos e suas principais características

\begin{tabular}{|l|l|l|l|}
\hline \multicolumn{2}{|c|}{$\begin{array}{c}\text { TIPOS DE SUJEITOS POR } \\
\text { ORDEM DE OCORRÊNCIA }\end{array}$} & $\begin{array}{c}\text { PERCENTUAL EM } \\
\text { RELAÇÃOAO TOTAL } \\
\text { DE SUJEITOS }\end{array}$ & \multicolumn{1}{c|}{$\begin{array}{c}\text { CARACTERÍSTICAS } \\
\text { PRINCIPAIS }\end{array}$} \\
\hline ELÍPTICO & $35 \%$ & $\begin{array}{l}42 \% \text { em formas nominais } \\
\begin{array}{l}37,91 \% \text { em verbos na } 3^{\mathrm{a}} \text { pessoa } \\
\text { do plural }\end{array}\end{array}$ \\
\hline REALIZADO & Pré-verbal & $33 \%$ & $94 \%$ com até 10 palavras \\
\hline & Pós-verbal & $16 \%$ & $77,12 \%$ com até 10 palavras \\
\hline & Pronominal & $12 \%$ & $69 \%$ por pronome relativos \\
\hline & Oracional & $4 \%$ & $45,48 \%$ orações reduzidas \\
\hline
\end{tabular}

\section{Considerações Finais}

Os dados encontrados nas análises deste estudo-piloto parecem comprovar que a linguagem empregada nas Sentenças dos JECs nem sempre atende aos princípios da art. $2^{\circ}$ da Lei 9.099/95, entre eles os da simplicidade e da informalidade. Afinal, a simplicidade na linguagem, como vimos até aqui, não combina com períodos longos de 1 frase só com vários níveis de subordinação. Não combina também com um percentual de $63 \%$ de sujeitos (elípticos, pós-verbais e pronominais) que demandam maior sobrecarga na memória de trabalho do leitor.

$\mathrm{Na}$ continuidade de nossa pesquisa, confrontaremos os dados aqui apresentados com os de outros corpora. Buscaremos especialmente acervos de jornais populares (como o PorPopular: http://www.ufrgs.br/textecc/porlexbras/porpopular/). Assim, esperamos 
verificar o quanto a apresentação desses CFsSujeitos aproxima-se ou não da linguagem cotidiana escrita em nosso país.

\section{Referências}

Bourigault, D. Slodzian, M. (2004) "Por uma terminologia textual”, In: Krieger e Araújo (orgs.). Cadernos de Tradução, Porto Alegre: Instituto de Letras, Universidade Federal do Rio Grande do Sul, p. 29-32.

Brasil. (1995) "Lei n 9.099, de 26 de setembro de 1995", Lei dos Juizados Especiais.

Coscarelli, C. V. (2002) "Entendendo a Leitura”, Estudos da Linguagem, Belo Horizonte, v. 10, n. 1, p. 7-27, jan./jun.

Fulgêncio, L. e Liberato, Y. (2010) "É possível facilitar a leitura: um guia prático para escrever claro", São Paulo: Contexto.

Krieger, M. G. e Finatto, M. J. B. (2004) "Introdução à terminologia: teoria e prática", São Paulo: Contexto.

Leal, S. E. (2019) "Predição da complexidade sentencial do português brasileiro escrito, usando métricas linguísticas, psicolinguísticas, e de rastreamento ocular”, 132 p., Monografia (Doutorado em Ciências - Ciências de Computação e Matemática Computacional) - Instituto de Ciências Matemáticas e de Computação, Universidade de São Paulo, São Carlos - SP.

Rio Grande do Sul. Poder Judiciário do Rio Grande do Sul. (2019) "Processo n ${ }^{\circ} 9002991$ 14.2018.8.21.0029”, Comarca de Santo Ângelo, julgado em 23-09-2019. 